\title{
PEMODELAN REAKTOR BIOGAS MENGGUNAKAN MODEL SISTEM DINAMIK UNTUK MENINGKATKAN EFISIENSI DAN BIAYA PEMBUATAN
}

\author{
${ }^{1}$ Amir \\ ${ }^{2}$ Murtalim \\ ${ }^{12}$ Program Studi Teknik Mesin, Fakultas \\ Program Studi, Fakultas Teknik dan Ilmu Komputer, Universitas Buana Perjuangan \\ Karawang \\ 1 amir@ubpkarawang.ac.id \\ ²murtalim@ubpkarawang.ac.id
}

\begin{abstract}
ABSTRAK
Penelitian ini bertujuan untuk menyusun model sistem dinamik yang menggambarkan hubungan sub-sistem proses biogas, sosial ekonomi, dan sumber bahan bakar alternatif pada reaktor biogas. Sumber bahan biogas pada penelitian ini adalah kotoran sapi. Selain itu, penelitian ini juga bertujuan untuk membuat prediksi kondisi dan produksi biogas untuk 5 tahun ke depan. Model disusun menggunakan pendekatan sistem dinamik. Variabel yang menjadi faktor dalam model adalah jumlah dan komposisi kotoran sebagai bahan alternatif, proses kimia pada reaktor biogas, dan kondisi sosial ekonomi peternak. Hasil penelitian diharapkan dapat memberikan gambaran tentang proses reaksi biogas, sehingga dapat memprediksi produksi dan efisiensi yang dihasilkan dari reaktor biogas. Penelitian ini juga diharapkan mampu memprediksi ukuran dan spesifikasi biogas yang efektif sehingga dapat memberikan masukan untuk rekayasa reaktor biogas.
\end{abstract}

Kata kunci: Biogas; digester; kotoran sapi; sistem dinamik.

\section{PENDAHULUAN}

Saat ini, energi panas telah menjadi kebutuhan pokok bagi setiap masyarakat. Penggunaan bahan bakar gas untuk kebutuhan rumah tangga sudah sejak lama dicanangkan oleh pemerintah dalam menggantikan minyak tanah. Namun, harga bahan bakar gas bagi masyarakat terus meningkat. Oleh karena itu, biomassa diperlukan sebagai bahan bakar alternatif. Salah satu biomassa adalah kotoran sapi yang dapat dikonversi menjadi bioenergi (biogas) (Ignacio Contreras-Andrade, Jonathan Parra-Santiago, \& Carlos Alberto GuerreroFajardo, 2015). 
Bioenergi yang berasal dari biomassa mungkin memainkan peran penting dalam sistem energi masa depan karena pembaruan dan keberlanjutannya. Distribusi biomassa yang luas menyediakan sumber bahan baku yang kaya material, sedangkan perkembangan signifikan dalam teknologi konversi bioenergi telah meningkatkan daya saingnya (Rincón et al. 2014). Bioenergi yang digunakan untuk menghasilkan biofuel, panas, dan listrik, dapat dihasilkan melalui berbagai jalur seperti proses termo-kimia, biologis, dan bio-elektrokimia (Haugen, Bakke, and Lie 2013). Sistem bioenergi harus dioptimalkan untuk memastikan keberlanjutannya, memaksimalkan efisiensinya, dan meminimalkan biaya.

Bioreaktor merupakan unit penting dalam konversi mikroba proses, karena menyediakan tempat yang cocok dan stabil untuk pertumbuhan dan metabolisme mikroba dengan mengontrol kondisi operasi (Karambelkar 2018). Kinerja bioreaktor sangat dipengaruhi oleh banyak faktor lain, seperti struktur dan ukuran bioreaktor, karakteristik pencampuran dan transfer, dan cara pemasukan pakan dan pembuangan produk (Saracevic et al. 2017). Terdapat pola aliran multifase kompleks yang ada pada bioreaktor yang dapat memvariasikan karakteristik perpindahan panas dan massa dalam bioreaktor dan mempengaruhi proses konversi mikroba (Karambelkar 2018).

Beberapa metode telah digunakan untuk menyusun model dan simulasi pada reaktor biogas yaitu model orde pertama, model Gompertz, dan model logistik (Salgado, 2019; Saeed et. Al., 2019; Ignacio et. Al., 2015; Suleiman \& Dorcas, 2020. Model Gompertz dianggap yang terbaik model. Model Gompertz menggambarkan pertumbuhan hewan dan tumbuhan serta volume bakterinya. Ini juga menjelaskan kurva produksi biogas kumulatif dalam destruksi batch, dengan asumsi bahwa tingkat substrat membatasi pertumbuhan dalam hubungan logaritmik (Suleiman Momodu and Dorcas Adepoju 2020).

Model dan simulasi di atas tidak mengkaitkan faktor sosial ekonomi dan spesifikasi bioreaktor. Sehingga penelitian ini bertujuan untuk menyusun model sistem dinamik yang menghubungkan proses biogas, sosial ekonomi, dan sumber bahan bakar alternatif pada reaktor biogas.

\section{METODE PENELITIAN}

\section{Jenis Penelitian}

Penelitian ini merupakan penelitian berbasis model matematis. Model yang akan dibangun adalah model sistem dinamik pada kasus biogas. Persamaan yang digunakan adalah persamaan matematis dengan fungsi turunan pertama dan kedua. 


\section{Waktu dan Tempat Penelitian}

E ISSN : 2580-5517

Penelitian ini dilakukan pada Bulan Maret 2021 sampai dengan Oktober 2021. Model simulasi reaktor biogas ini disusun berdasarkan bioreaktor di Desa Nagrog, Kecamatan Wanayasa, Kabupaten Purwakarta, Jawa Barat. Secara khusus yang menjadi masyarakat sasaran di program ini adalah Kampung Tegalega, Desa Nagrog.

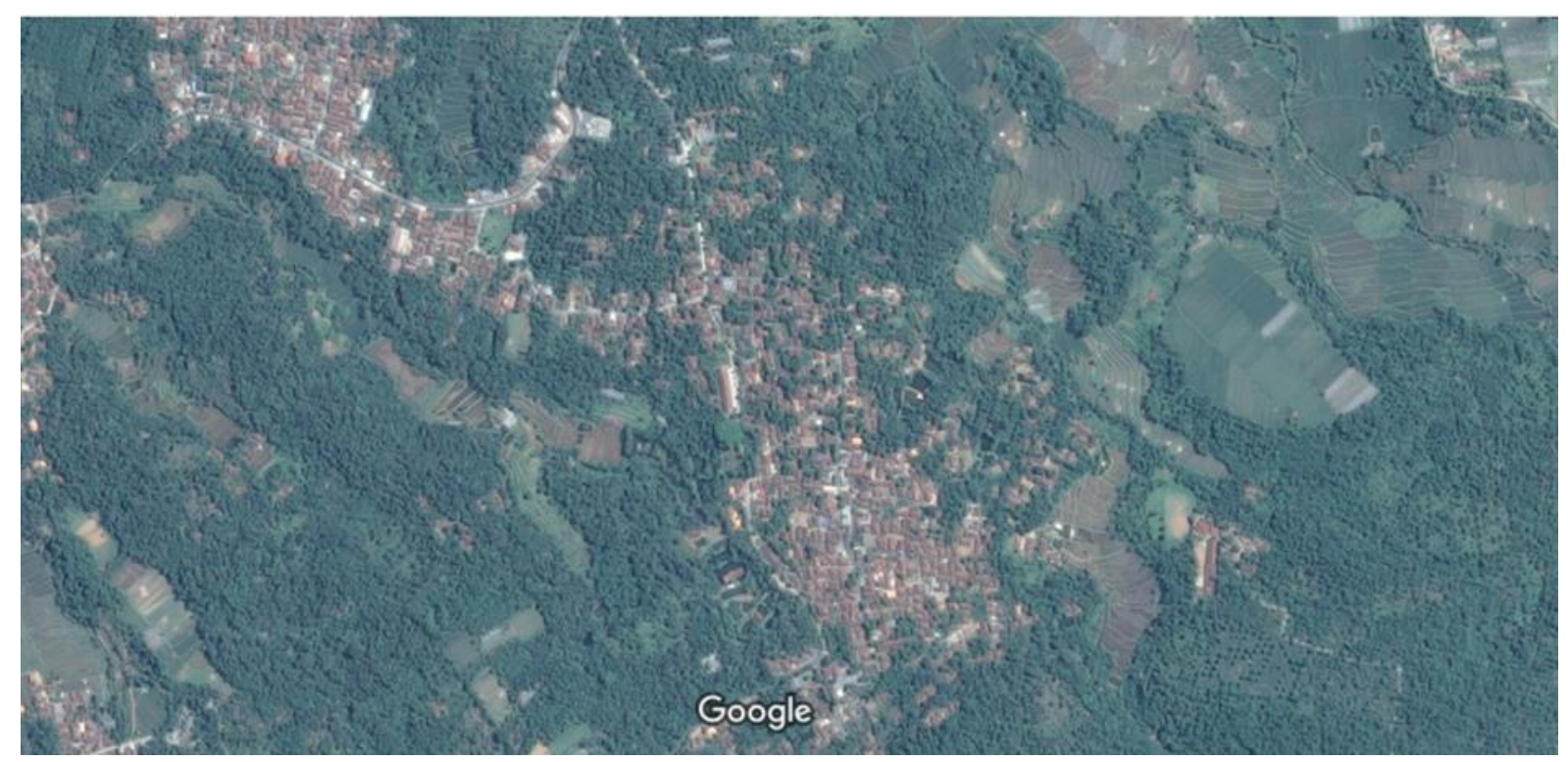

Gambar 3.2. Peta Wilayah Kampung Tegalega, Desa Nagrog, Wanayasa, Purwakarta.

\section{Target/Subjek Penelitian}

Wilayah Desa Nagrog yang akan dijadikan target atau subyek penelitian. Wilayah ini merupakan mayoritas wilayah peternak sapi potong dan kerbau. Jumlah sapi potong di Desa Nagrog sebanyak 67 ekor, sapi perah 2 ekor, dan kerbau 23 ekor (Kecamatan Wanayasa Dalam Angka Tahun 2015). Kampung Tegalega sendiri mempunyai Kelompok Tani Sapi Potong Makmur Jaya. Permasalah dari kelompok tani ini adalah kotoran sapi yang dihasilkannya. Kotoran sapi yang dihasilkan akan menyebabkan bau dan masalah bagi lingkungan di sekitar kampung. Salah satu cara untuk mengatasi ini adalah dengan membangun reaktor biogas. Kondisi saat ini, kampung Tegalega baru memiliki 7 reaktor biogas ukuran kecil yang hanya mampu digunakan untuk 7 rumah tangga.

\section{Prosedur Penelitian}

Gambar 1 menunjukkan tahapan prosedur penelitian. Penelitian ini dimulai dari studi literatur. Dalam Studi literatur, peneliti melakukan pencarian referensi buku dan jurnal penelitian yang terkait dengan aliran air danau dan sistem dinamik. Setelah studi literatur, dilanjutkan dengan penyusunan kuisioner dan persiapan administrasi surat menyurat. Setelah itu, tahapan dilanjutkan dengan pengambilan data ke lapangan. Data yang diambil adalah data primer dan 
data sekunder. Tahapan selanjutnya yaitu entry data ke komputer sebagai master data penelitian. Berikutnya, peneliti menyusun model sistem dinamik dan melakukan analisa data berdasarkan master data yang telah dibuat. Hasil analisa data kemudian ditampilkan dalam bentuk tabel dan grafik. Tahapan terakhir adalah pembuatan laporan. Pada tahapan ini, tim peneliti menyusun laporan akhir penelitian dan draft jurnal penelitian.

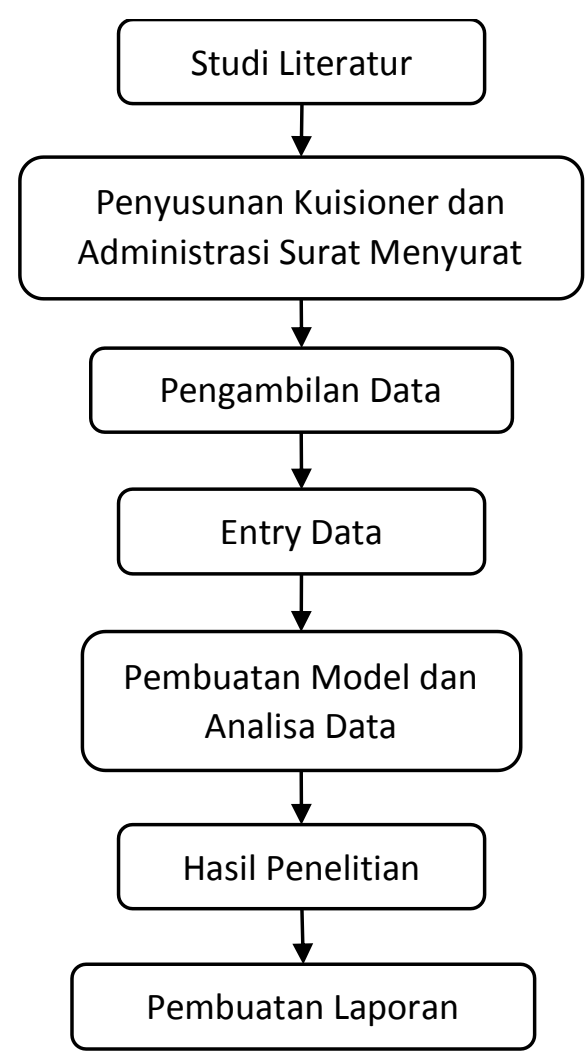

Gambar 1. Tahapan Penelitian.

\section{Data, Instrumen, dan Teknik Pengumpulan Data}

Penelitian ini menggunakan pendekatan sistem dinamik untuk Reaktor Biogas (Ford, 1999). Model sistem dinamik terdiri dari empat komponen yaitu: 1) Stock (state variable, level, atau reservior); 2) Flow (rerata/laju, variabel kontrol, atau proses); 3) Conventer (auxilliary atau variabel translasi); dan 4) Connector (atau panah informasi). Keseluruhan model sistem dinamik disusun berdasarkan dua atau lebih sub-sistem. Pada penelitian ini, sub-sistem yang digunakan adalahsub-sistem Environmental Flow (debit air masuk, debit air keluar, presipitasi, dan evaporasi), sub-sistem ketinggian air danau, dan sub-sistem sosial ekonomi (pengolahan air minum).Pengumpulan data untuk konsisi sosial ekonomi dilakukan melalui survey menggunakan form kuisioner. Data variabel lainnya yang diambil berasal dari 
sekunder dan data primer. Analisa data menggunakan pendekatan sistem dinamik dimana setiap variabel dalam sistem merupakan fungsi non linear (eksponensial).

\section{Teknik Analisis Data}

Untuk menggambarkan pola hubungan antar sub-sistem, model sistem dinamik memanfaatkan persamaan non-linear seperti pada Persamaan 3.1.

$$
\frac{d X_{i}(t)}{d t}=f\left(X_{i}, R_{i}, A_{i}, C_{i}\right)
$$

Penyelesaian persamaan turunan (3.1) dapat ditulis sebagai berikut

$$
X_{\mathrm{i}}(t+\Delta t)=X_{\mathrm{i}}(t)+f\left(X_{\mathrm{i}}, R_{\mathrm{i}}, A_{\mathrm{i}}, C_{\mathrm{i}}\right)^{*} \Delta t
$$

Pada sistem dinamik, penyelesaian Persamaan 3.2 menggunakan analisa numerik seperti deret Euler, dan Rangge-Kutta.

Untuk membangun model sistem dinamik pada reaktor biogas, peneliti mengambil variabelvariabel sebagai berikut:

1. Kondisi iklim mikro (suhu lingkungan, kelembaban, tekanan udara, dan intensitas cahaya)

2. Debit aliran inlet

3. Jumlah massa dan $\mathrm{pH}$ limbah kotoran sapi

4. Proses reaksi kimia pada digester

5. Evaporasi pada sekitar bioreaktor

6. Jumlah biogas dan tekanan digester pada reaktor.

7. Kondisi sosial ekonomi masyarakat

\section{HASIL PENELITIAN DAN PEMBAHASAN}

\section{Hasil Penelitian}

\section{Pembangunan Model}

Dinamika sistem digunakan untuk menganalisis dan memprediksi sistem yang kompleks berdasarkan data empiris dan asumsi serta menguji model dengan data terbatas. Causal loop diagram (CLD) digunakan untuk menggambarkan hubungan antar variabel menggunakan rantai sebab akibat yang tertutup (Kotir et al. 2016). Gambar 2 menunjukkan hubungan variabel dari subsistem yang terdapat pada pengolahan biogas.CLD dikembangkan melaui data sekunder dan primer serta wawancara mendalam dengan kelompok ternak. 


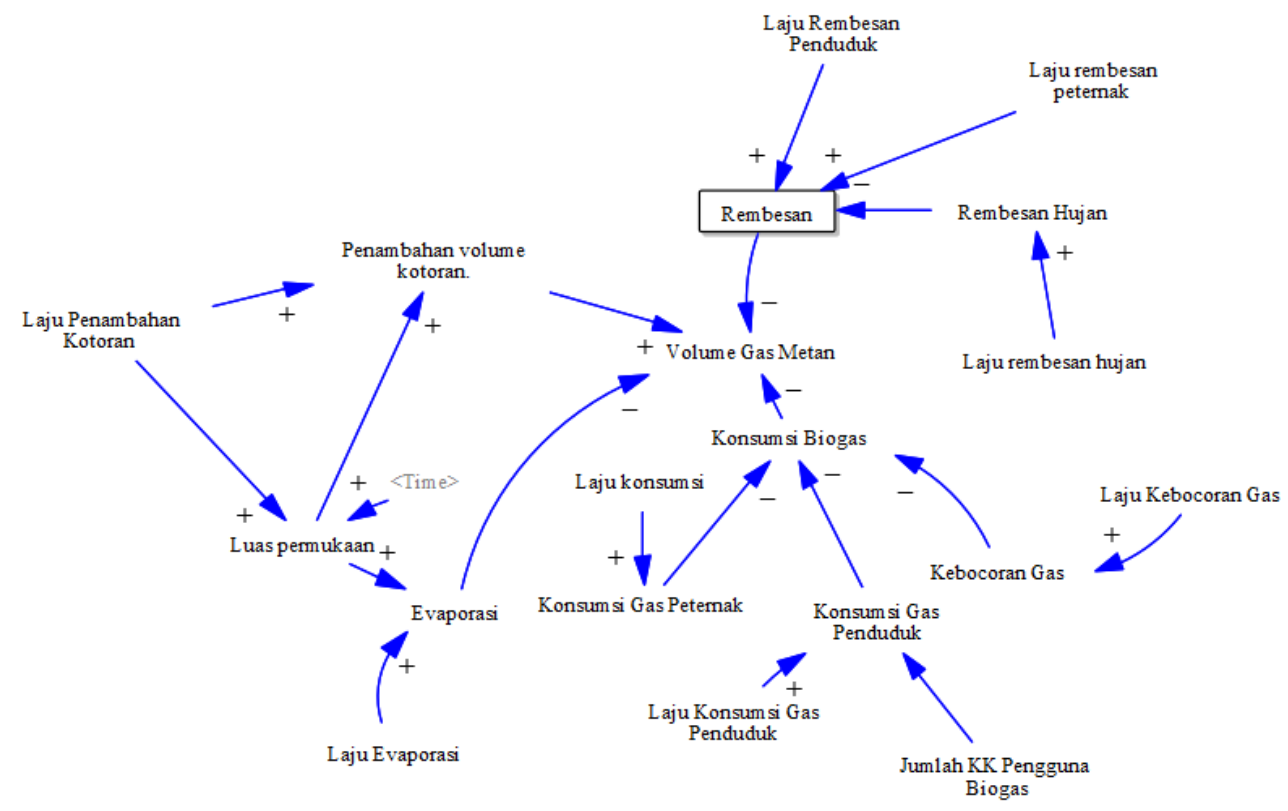

Gambar 2. Causal Loop Diagram untuk Model Biogas.

Model sistem dinamis pada biogas terdiri dari empat komponen: 1) Stok (variabel keadaan, level, atau reservoir); 2) Aliran (rata-rata / laju, variabel kontrol, atau proses, konstanta); 3) Konverter (variabel bantu atau translasi); dan 4) Konektor (atau informasi panah). Jenis variabel ini ditunjukkan pada Gambar 2. Variabel stok merupakan variabel dengan persamaan integrasi numerik yaitu nilai variabel yang dipengaruhi oleh waktu. Variabel jenis ini adalah Luas permukaan. Variabel aliran merupakan variabel kontrol atau laju perubahan yang mempengaruhi variabel lainnya. Misalnya pada model evaporasi adalah konstan sehingga termasuk jenis variabel aliran. Variabel konvensional merupakan variabel yang tidak dipengaruhi oleh waktu tetapi hanya dipengaruhi oleh variabel bebas lainnya. Misalnya variabel konsumsi gas dipengaruhi oleh variabel konsumsi biogas. Variabel stock and flow yang digunakan dalam penelitian ini ditunjukkan pada Tabel 1.

Table 1. Variabel Stokpada Model Sistem Dinamik Biogas.

\begin{tabular}{llrc}
\hline \multicolumn{1}{c}{ Tipe Variabel } & \multicolumn{1}{c}{ Variabel } & Nilai Awal & Satuan \\
\hline Stock & Volume Gas Metan & 70 & $\mathrm{~m}^{3}$ \\
\hline & Konsumsi Biogas & 0 & $\mathrm{~m}^{3}$ \\
\hline & Rembesan & 0.05 & $\mathrm{~m}^{3}$ \\
\hline & Evaporasi & 0.08 & $\mathrm{~m}^{3}$ \\
\hline Kebocoran Gas & 0.01 & $\mathrm{~m}^{3}$ \\
\hline & Luas permukaan & 25 & $\mathrm{~m}^{2}$ \\
\hline & Penambahan volume kotoran & 25 & $\mathrm{~m}^{3}$ \\
\hline
\end{tabular}


Nilai awal pada Tabel 1 diperoleh dari hasil analisis kuesioner, dan data sekunder dari

Kelompok Ternak di Wanayasa.

\section{Persamaan Dasar Model}

Setiap subsistem memiliki persamaan matematis yang merepresentasikan interaksi antar variabel. Sumber daya gas dipengaruhi oleh nilai supply dan demand gas, sehingga persamaan tersebut diwakili oleh Persamaan 3.

Volumen Gas Metan = (Rembesan+"Penambahan volume kotoran."+Air

Rembesan+Waste water-Konsumsi Biogas-Evaporasi)

\section{Hasil Simulasi Model}

Simulasi dan prediksi model dilakukan hingga tahun 2022. Berdasarkan data awal dan persamaan model, setelah program simulasi dijalankan ditunjukkan pada Gambar 2.
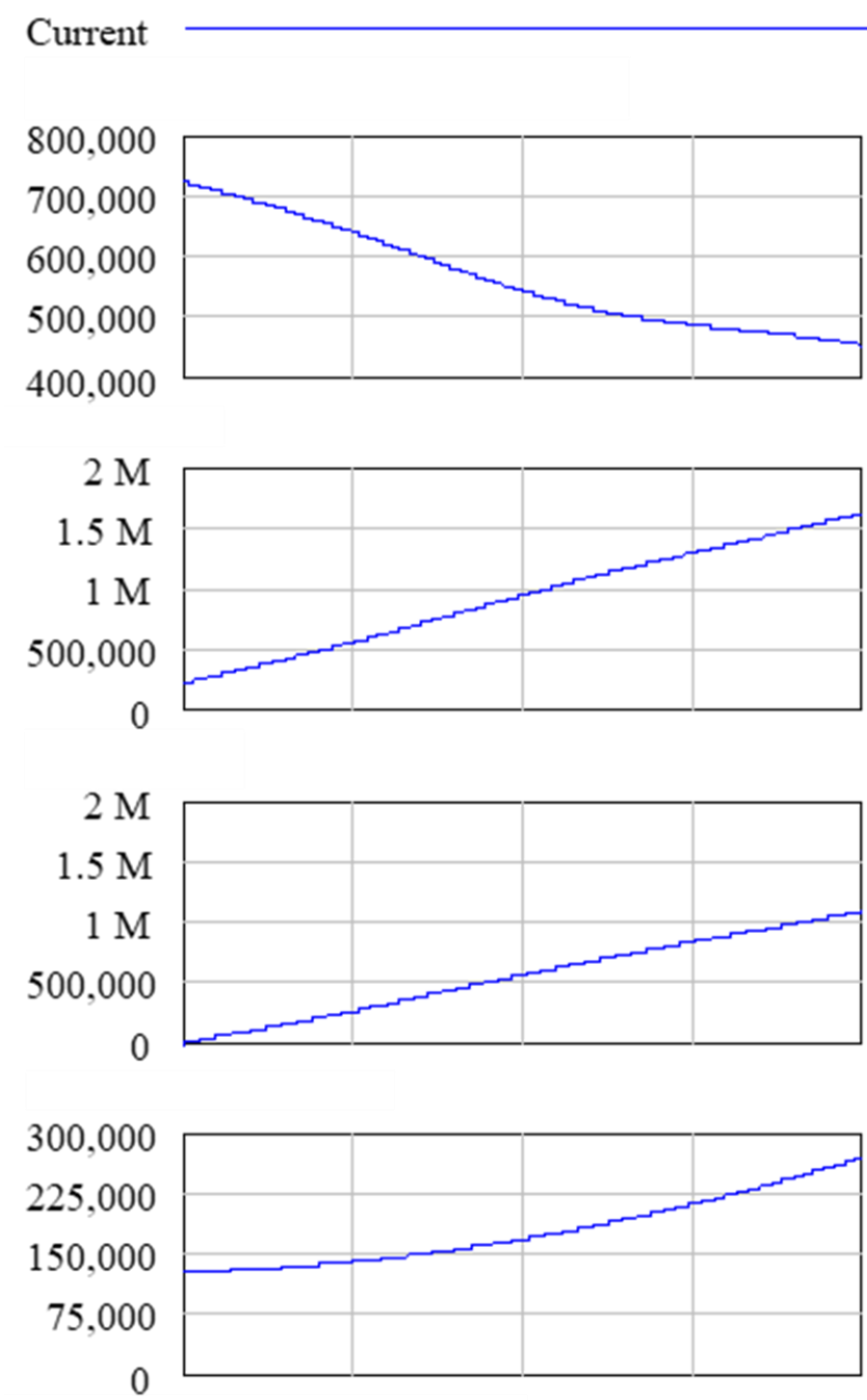

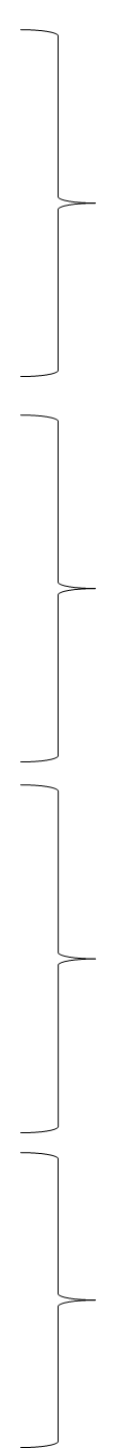

Penambahan volume kotoran

Air Rembesan

Konsumsi Biogas Evaporasi

Gambar 2. Hasil Model Simulasi Biogas. 
Berdasarkan hasil simulasi model (Gambar 2), volume gas metan yang diproduksi reaktor biogas berkurang setiap tahunnya. Hal ini menunjukkan bahwa sumber daya gas terus digunakan, maka perlu adanya maintenance secara periodik minimal 2 tahun sekali.

\section{Pembahasan}

Penggunaan biogas untuk keperluanrumah tangga sebagai sumber energi sangatmenguntungkan. Apabila dibandingkan denganbahan bakar tradisional misalnya kayu. Variabel yang mempengaruhi produksi biogas adalah kondisi anaerobik, bahan atau campuran bahan, suhu, tingkat kepedasan $(\mathrm{pH})$, aksesibilitas nutrisi, pencampuran, zat beracun, dan pelemahan (kadar air). Namun, sedikit penyimpangan komposisi dari pemborosan campuran juga mempengaruhi jumlah metana yang akan dihasilkan dalam produksi biogas. Pencampuran kedua quander dapat mempengaruhi nilai tingkat keasaman $(\mathrm{pH})$, proporsi $\mathrm{C} / \mathrm{N}$ dan penurunan (kadar air). Dalam penelitian ini diarahkan untuk mengetahui pengaruh varietas dalam penyelenggaraan pengujian kombinasi limbah kelapa sawit dan kotoran sapi.

\section{KESIMPULAN DAN IMPLIKASI}

Berdasarkan hasil simulasi, dapat disimpulkan bahwa kebutuhan sumber daya biogas setiap tahun semakin meningkat. Kondisi ini disebabkan karena reaktor merupakan sumber gas metan utama bagi masyarakat di Wanayasa dan secara khusus di wilayah Kelompok Ternak. Meskipun masyarakat banyak yang menggunakan gas dari Elpiji dan bahan bakar kayu, tetapi keduanya bukan merupakan sumber energi alternatif yang bersumber dari lingkungan sekitar. Sehingga diperlukan sumber energi alternatif bagi masyarakat yaitu biogas. Reaktor biogas ini jika digunakan akan mengalami penurunan kualitas dan kuantitas produksi biogas. Oleh karena itu, diperlukan perawatan secara berkala agar jumlah dan kualitas gas metan terjaga.

\section{UCAPAN TERIMA KASIH}

Penelitian ini dapat terselenggara dengan bantuan dari Dana Penelitian Dosen Pemula Tahun Anggaran 2021 yang diberikan oleh Kementrian Pendidikan dan Kebudayaan dengan Nomor Kontrak 065/SP2H/LT/DRPM/2021; 030/SP2H/RDPKR-MONO/LL4/2021; dan 01/LPPM/PDP/VII/2021.

\section{DAFTAR PUSTAKA}


1. Borshchev, A., dan Filippov, A., 2004., From System Dynamics and Discrete Event to Practical Agent Based Modeling: Reasons, Techniques, Tools. The 22nd International Conference of the System Dynamics Society, July 25 - 29, 2004, Oxford, England.

2. Ford, A., 1999., Modeling the Environment: An Introduction to System Dynamics Models of Environmental Systems., Island Press: Washington D.C.

3. Haugen, Finn, Rune Bakke, and Bernt Lie. 2013. "Adapting Dynamic Mathematical Models to a Pilot Anaerobic Digestion Reactor." Modeling, Identification and Control 34(2): 35-54.

4. Ignacio Contreras-Andrade, Jonathan Parra-Santiago, and Carlos Alberto GuerreroFajardo. 2015. "Simulation of Biogas Production from Solid Organic Wastes." Journal of Chemistry and Chemical Engineering 9(2): 107-12.

5. Karambelkar, Shruti Shrikant. 2018. "Effect of Variation of Parameters on Biogas Production Using Aspen Plus \&amp; Dynamic Simulation Using Mimic.” ProQuest Dissertations and Theses: 51 .

6. Rincón, Alejandro, Julieta Villa, Fabiola Angulo, and Gerard Olivar. 2014. "A Dynamic Analysis for an Anaerobic Digester: Stability and Bifurcation Branches." Mathematical Problems in Engineering 2014.

7. Saeed, Mohammed, Samaa Fawzy, and Magdi El-Saadawi. 2019. "Modeling and Simulation of Biogas-Fueled Power System." International Journal of Green Energy 16(2): 125-51.

8. Salgado, Juan Antonio Arzate. 2019. "Modeling and Simulation of Biogas Production Based on Anaerobic Digestion of Energy Crops and Manure." Master Thesis: 178.

9. Saracevic, Ervin, David Woess, Anton Friedl, and Angela Miltner. 2017. "Dynamic Simulation of a Biogas Plant Providing Control Energy Reserves.” Chemical Engineering Transactions 61: 931-36.

10. Suleiman Momodu, Abiodun, and Tofunmi Dorcas Adepoju. 2020. "System Dynamics Model of the Kinetics of Biogas Production from Vegetal Matter." International Journal of Energy and Power Engineering 9(2): 22.

11. Wei, S., Yang, H., Song, J., Abbaspour, K.C., Xu, Z., 2012., System Dynamics Simulation Model for Assessing Socio-Economic Impacts of Different Levels of Environmental Flow Allocation in the Weihe River Basin, China., European Journal of Operational Research. 221 (2012): 248-262 